DOI: https://doi.org/10.47405/mjssh.v5i7.443

\begin{tabular}{|c|c|}
\hline 4 & Malaysian Journal of Social Sciences and Humanities (MJSSH) \\
\hline $\begin{array}{l}\text { Malaysian Journal of } \\
\text { Social sciences and }\end{array}$ & Volume 5, Issue 7, July 2020 \\
\hline (MJ-SSH) & e-ISSN : 2504-8562 \\
\hline & $\begin{array}{l}\text { Journal home page: } \\
\text { www.msocialsciences.com }\end{array}$ \\
\hline
\end{tabular}

\title{
Openness Personality Trait on Local Government Information System Services: An Overview
}

\author{
Mohd Zool Hilmie Mohamed Sawal', Azlizan Talib ${ }^{2}$, Kamarudin Ngah ${ }^{2}$ \\ ${ }_{1}^{1}$ Faculty of Information Management, Universiti Teknologi MARA (UiTM) Cawangan Kedah \\ 2School of Government College of Law, Government and International Studies, Universiti Utara Malaysia (UUM) \\ Correspondence: Mohd Zool Hilmie Mohamed Sawal (zoolhilmie@uitm.edu.my)
}

\begin{abstract}
This paper investigates the adaptation of one of the Big Five Personality traits namely Openness in local community acceptance toward local government information system. The data collected via survey based on Openness statement taken from Big Five Personality Inventory item. This is to gain idea regarding acceptance on information system such as information system services in local government agencies in Northern Malaysia that has been introduced to them. Questionnaires has been distributed to collect data and has been analyzed using statistical software. Analyses such as percentage and correlation are been executed to differentiates and tabulate the data to readable results. The findings of the study believe could give the idea to the local government or local authority in providing better services to their community.
\end{abstract}

Keywords: personality traits, Big Five, local government, information system, openness

\section{Introduction}

Rapid development of information technology nowadays gives changes on the way we live and work substantially. Malaysia is actively improving its infrastructure in giving the best services to its citizen. For example, the local government has improving it services to local community via information system such as electronic services. It considers as an efficient medium of services delivery to community (Mohd Nazri, 2008). In Malaysia, the development information system network started in 1987 by MIMOS (Malaysian Institute of Microelectronic Systems) which setup network call RangKom (Rangkaian Komputer Malaysia) which connects several universities. In previous era, RangKom provides services such as e-mail and news group services to the community. The rapid growth of network nowadays resulted big impacts on people lifestyle. How they perceive and the people acceptance on the services provided by the local government agencies. The internet growth contributes to the changes of information flow to the society. Internets is defined as interconnected networks using standardize communication protocol. Thus, indirectly eliminate geographical and time barriers. Even the government had spent a lot of money in proving the infrastructure to cater the needs of society, for example in 2019 the allocation budget estimated is more than RM 415,000,000.000 and this figure increases more to than RM 813,000,000.00 under The Ministry of Communications and Multimedia for year 2020 (Ministry of Finance, 2019). This shows the importance of the technology in these days. The purpose of this paper is to explore personality traits of acceptance information system based on Big Five Personality traits namely openness. This study attempts to find out the relationship between the two variables which are openness and acceptance. 
Personality represents the individual behavior pattern through which can be identified by individual adaptation or reaction to the surrounding environment. This study adopts the Big Five Personality Traits as model in categorizing personality. This model derived from Allport, and Odbert early work to describe personality characteristics in English language (Allport \& Odbert, 1936). Their work set as primary starting point in understanding people personality traits (Howard \& Howard, 2004). Openness Personality for the Big Five Personality Traits is adopted in this study. The Openness Personality Trait consider the important domain in Big Five (Kaufman, 2013). This can be defined as degree to which individuals exhibit intellectual curiosity, self-awareness, and individualism. Openness are people or person who portray characteristic who willing to encounter a wide variety of ideas, feelings, and activities (McCrae \& Greenberg, 2014). Such persons or peoples are willing to consider new ideas and alternative principles (Nayyar, Rana, Farheen, Ghazala \& Mohammad Taqi, 2012). These people are categorized as the people who go with the changes for better such as from using the physical services to virtual or electronic based services. Ideally this type of personality person who is ready and have open minded towards new changes occurring around them with resulted them happiness and ease. Relating with acceptance. It can be defined as readiness to accept or usage of something or someone in their life. Acceptance can be related with mutual understanding with two or more parties (Dewall \& Bushman, 2011) which can lead to happiness or better cooperation between those parties. Relating with information system, acceptance reflect the readiness to use the system as daily routine or lifestyle if needed.

\section{Methodology}

The data for this paper were collected through questionnaire. A total of 400 questionnaires were distributed around Sungai Petani district. From this, 45 questionnaires were incomplete which resulted only 355 questionnaires findings is used for this analysis which contributed to 88.75 percent of the valid response. The collected questionnaire been analyses to get alpha value for reliability for Openness Personality trait and acceptance. The alpha value for each variable is 0.811 and 0.847 which is acceptable because the minimum acceptable value is 0.70 or 0.6 (Griethuijsen, et al., 2014). The statements for the questionnaire related with Openness Personality is taken from Big Five personality traits. The statements had been categories in related personality (Goldberg, 1993; John \& Srivastava, 1999).

\section{Result}

This study analyzed 355 questionnaires. From the total respondents, 166 respondents are male, and 189 respondents are female. Majority of the respondents age between 28 years old and above, while total of 200 respondents are age between 19 years old to 27 years old. The statement used in the questionnaire survey are taken from Big Five Inventory items. The inventory is design in short statement or phrases to make it easy to understand (John, Donahue \& Kentle, 1991; Benet-Martinez \& John, 1998; John,Naumann \& Soto, 2008).

Based on table 1, the table indicate ten statement related with Openness Personality. Each statement has its own understanding. Based on the ten statement the top three highest statement indicate by the respondent are prefers work that is routine, statement is curious about many different things and statement Likes to reflect, play with ideas. Each of the statement carry value of 223, 211 and 210 respondents. However, if combine the respondent's opinion between agree and strongly agree, the top three statement are different which are statement is curious about many different things, statement is ingenious, a deep thinker and statement is original, comes up with new ideas. the value of each combine value is 305,282 and 271 respondents. 
Table 1: Openness Statements

\begin{tabular}{clcccc}
\hline No & Openness Statements & $\begin{array}{c}\text { Strongly } \\
\text { Disagree }\end{array}$ & Disagree & Agree & $\begin{array}{c}\text { Strongly } \\
\text { Agree }\end{array}$ \\
\hline \multirow{2}{*}{1} & Is original, comes up with new & 16 & 68 & 195 & 76 \\
& ideas & $(4.5)$ & $(19.2)$ & $(54.9)$ & $(21.4)$ \\
2 & Is curious about many different & 11 & 39 & 211 & 94 \\
& things & $(3.1)$ & $(11.0)$ & $(59.4)$ & $(26.5)$ \\
3 & Is ingenious, a deep thinker & 6 & 67 & 209 & 73 \\
& & $(1.7)$ & $(18.9)$ & $(58.9)$ & $(20.6)$ \\
4 & Has an active imagination & 7 & 88 & 187 & 73 \\
& & $(2)$ & $(24.8)$ & $(52.7)$ & $(20.6)$ \\
5 & Is inventive & 13 & 99 & 187 & 56 \\
& & $(3.7)$ & $(27.9)$ & $(52.7)$ & $(15.8)$ \\
6 & Values artistic, aesthetic & 17 & 77 & 193 & 68 \\
& experiences & $(4.8)$ & $(21.7)$ & $(54.4)$ & $(19.2)$ \\
7 & Prefers work that is routine & 11 & 67 & 223 & 54 \\
\multirow{2}{*}{8} & Likes to reflect, play with ideas & $(3.1)$ & $(18.9)$ & $(62.8)$ & $(15.2)$ \\
& & $(4.2)$ & $(22)$ & $(59)$ & $(14.6)$ \\
9 & Has few artistic interests & 23 & 85 & 194 & 53 \\
\multirow{2}{*}{10} & Is sophisticated in art, music, or & $(6.5)$ & $(23.9)$ & $(54.6)$ & $(14.9)$ \\
& literature & 37 & 94 & 162 & 62 \\
$*$ percentage value round at one decimal point & $(10.4)$ & $(26.5)$ & $(45.6)$ & $(17.5)$ \\
& & & &
\end{tabular}

Looking at the disagree and strongly disagree statement the combine values indicate the top three statement are is sophisticated in art, music, or literature, statement has few artistic interests and likes to reflect, play with ideas. The value of each statement which combine respondent's opinion disagree and strongly disagree are 131, 108 and 93 . The percentage value are 36.9 percent, 30.4 percent, and 26.2 percent.

Other statement such values artistic, aesthetic experiences indicate combine value of agree and strongly agree of 261 respondents, statement has an active imagination indicate of 260 respondents for combine opinion agree and strongly agree and last statement is inventive indicate combine value of agree and strongly agree of 243 respondents. The percentage combine values are 73.6 percent, 73.3 percent, and 68.5 percent.

Related with the information questionnaire statement, the questionnaire was distributed concurrently with the Openness questionnaire. Based on the analysis, several statements indicate positive opinion which respondent choose to agree and strongly agree. Statement like information system provided by my local authority or local government has an impact in my life indicate value of 266 respondents 89 respondents who choose to disagree and strongly disagree. Statements like information system is the best way of getting the task done indicate 287 positive opinion rather than 68 combine opinion who disagree and strongly disagree. Another statement information system is the best medium to interact local authority reveal 289 respondents give positive feedback compare 66 respondents give on contrary feedback. This statement indicates how people access information or lodge a report such as drainage problem, wild animal problem. Next statement, it would be difficult for me to do the task without information system show combine value 222 respondents rated as agree and strongly agree compare 133 respondents give disagree and strongly disagree. The different is between opinion is 86 respondents which is 25.1 percent. The value of the respondents is various because the respondent feedback based on their opinion and experience.

As for the relationship between Openness Personality traits toward acceptance of information system, the correlation analysis is been analyze using statistical software. As illustrated in figure 1. The result 
form data analyze indicate the $r=0.346$, this relationship is considered moderate because $r$ value range between $0-3-0.5$. Thus, if the hypothesis is being apply there is a positive relationship between openness personality trait and acceptance and information system.

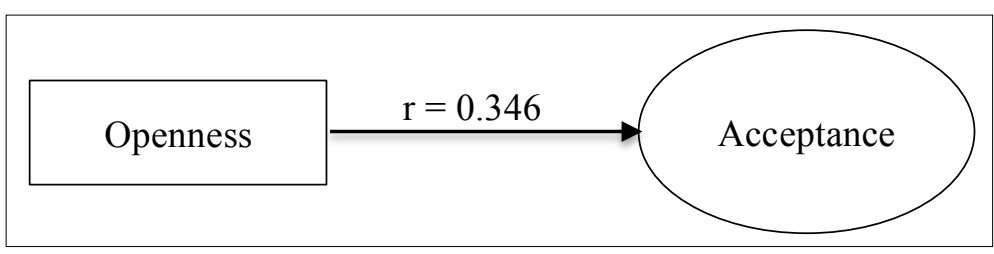

Figure 1: Relationship between variables

\section{Conclusion}

Personality trait is the categories of people or person to set of groups based on specific characteristics. Each of these traits have its own distinguish trademark that differ from each other's. As an example, Openness Personality trait by general definition is people who embrace or open changes. While acceptance in this study, reflect the people adoption toward information system that their local authority or local government introduce to them. From the outcome some of the respondents are happy to use while remaining does not prefer to use the information system. Whatever the result indicates, people favour is based on their own opinion and experiences. Technology nowadays is a norm and lead to changes of working and lifestyle at ease and more convenience. It helps to get, and share information needed faster and globally. (Mohd Zool, Kamarudin, \& Zaherawati, 2017). Best information system can lead to good governance.

As conclusion, the result would probably have different result if the study is done in various timeframe. This due the advancement of the information technology has evolved time by time. Even some of the administrative agencies had adopt these changes by embedded in daily administrative activities. As for user the chances lead them do adopt the changes in their daily.

\section{Acknowledgement}

This paper has been produced with the cooperation and great support from the staff of local authority agencies in Kedah. A special thanks to the respondent that give cooperation in giving their opinion and suggestion.

\section{References}

Allport, G. W., \& Odbert, H. S. (1936). Trait names: A psycholexical study. Psychological Monographs, 47- 211

Benet-Martinez, V., \& John, O. P. (1998). Los Cinco Grandes across cultures and ethnic groups: Multitrait multimethod analyses of the Big Five in Spanish and English. Journal of Personality and Social Psychology, 75, 729-750.

Dewall, C. N., \& Bushman, B. J. (2011). Social Acceptance and Rejection. Current Directions in Psychological Science, 20(4), 256-260. doi: 10.1177/0963721411417545

Goldberg, L. R. (1993). The Structure of Phenotypic Personality Traits. American Psychologist, 48(1) 26-34. doi:10.1037//0003-066x.48.1.26.

Griethuijsen, R. A. L. F. V., Eijck, M. W. V., Haste, H., Brok, P. J. D., Skinner, N. C., Mansour, N., Boujaoude, S. (2014). Global Patterns in Students' Views of Science and Interest in Science. Research in Science Education, 45(4), 581-603. doi: 10.1007/s11165-014-9438-6

Howard, P.J., and J.M. Howard (2004). The Big Five Quickstart: An Introduction to the Five-Factor Model of Personality. North Carolina: Center for Applied Cognitive Studies 
John, O. P., \& Srivastava, S. (1999). The Big-Five trait taxonomy: History, measurement, and theoretical perspectives. In L. A. Pervin \& O. P. John (Eds.), Handbook of personality: Theory and research (Vol. 2, pp. 102-138). New York: Guilford Press.

John, O. P., Donahue, E. M., \& Kentle, R. L. (1991). The Big Five Inventory--Versions 4a and 54. Berkeley, CA: University of California,Berkeley, Institute of Personality and Social Research.

John, O. P., Naumann, L. P., \& Soto, C. J. (2008). Paradigm Shift to the Integrative Big-Five Trait Taxonomy: History, Measurement, and Conceptual Issues. In O. P. John, R. W. Robins, \& L. A. Pervin (Eds.), Handbook of personality: Theory and research (pp. 114-158). New York, NY: Guilford Press.

Kaufman, S. B. (2013). Opening up Openness to Experience: A Four-Factor Model and Relations to Creative Achievement in the Arts and Sciences. The Journal of Creative Behavior, 47(4), $233-$ 255. doi: $10.1002 /$ jocb. 33

McCrae, R. R. and Greenberg, D. M. (2014). Openness to Experience. In the Wiley Handbook of Genius, D. K. Simonton (Ed.). doi:10.1002/9781118367377.ch12

Ministry of Finance. Estimated Federal Expenditure 2020 (2019). Retrieved from https://www.treasury.gov.my/index.php/en/budget/item/5546-estimated-federal-expenditure2020.html"

Mohd Nazri Mahmud (2008). Modeling the dynamics of internet adoption. Computer and Information Science, 1(1), 95-103.

Mohd Zool Hilmie Mohamed Sawal, Kamarudin Ngah, \& Zaherawati Zakaria. (2017). Identification of Information Variable toward Sound Decision Making among local Government Councillors. International Journal of Supply Chain Management, 6(1), 266-269. Retrieved from https://ojs.excelingtech.co.uk/index.php/IJSCM/article/view/1625

Nayyar Raza Zaidi, Rana Abdul Wajid, Farheen Batul Zaidi, Ghazala Batul Zaidi, \& Mohammad Taqi Zaidi. (2013). The big five personality traits and their relationship with work engagement among public sector university teachers of Lahore. African Journal of Business Management, 7(15), 1344-1353. doi: 10.5897/AJBM12.290 